\title{
Cell fate and cell morphogenesis in higher plants
}

\author{
John W Schiefelbein
}

\author{
University of Michigan, Ann Arbor, USA
}

\begin{abstract}
The differentiation of plant cells depends on the regulation of cell fate and cell morphogenesis. Recent studies have led to the identification of mutants and the cloning of genes that influence these processes. In several instances, the genes encode products with homeodomains or Myb or Myc DNA-binding domains.
\end{abstract}

Current Opinion in Genetics and Development 1994, 4:647-651

\section{Introduction}

In higher plants, the formation and differentiation of cells occurs in an orderly manner, often near meristems, which are groups of dividing cells that act like permanent stem cell populations. Cell differentiation in plants differs from that in animals because, for the most part, of a lack of the relative cell movements that are characteristic of animal development. Also, the rigid plant cell wall makes the control of cell shape a critical aspect of cell differentiation in plants.

The fate of undifferentiated plant cells is influenced primarily by cell position rather than cell lineage $[1,2]$. Thus, one of the current goals in studies of plant cell differentiation is to determine how cells acquire and respond to positional cues during development. Another goal is to understand how, once a particular fate is adopted, cell morphogenesis is regulated to generate a cell of the appropriate shape. The application of molecular genetic approaches have led recently to an understanding of some of the genes that participate in cell fate specification or cell morphogenesis in plants. This review will principally focus on these recent molecular and genetic experiments, including a summary of the rapidly growing number of homeobox genes that influence plant cell development and some of the model systems that are being used to study cell fate and morphogenesis in plants.

\section{Maize homeobox genes associated with cell fate}

The homeodomain is an approximately 60 amino acid DNA-binding domain found in a superfamily of eukaryotic proteins, some of which regulate cell fate $[3,4]$. The first plant homeobox gene to be isolated, KNOTTED1 (KN1), is associated with dominant neomorphic mutations that alter leaf development in maize and cause excess cell proliferation (knots) along lateral veins of the leaf blade ([5]; reviewed in [6]). The phenotype of $K n 1$ mutants led to the early notion that $K N 1$ influences the fate of leaf cells. Recent studies have shed light on the normal role of $K N 1$. In localization experiments, KN1 is undetectable in leaves, but it is abundant in the apical meristem and the immature axes of vegetative and floral shoots [7]. Also, the dominant $K n 1-N 2$ mutation has been found to cause ectopic expression, such that KN1 transcripts and $\mathrm{KN} 1$ protein are detected in lateral veins of developing leaves (in addition to the normal accumulation in the meristem), which correlates well with the alterations in leaf cell fate and knot formation associated with Kn1 mutants [7]. When the KN1 cDNA is expressed in tobacco under the control of the strong cauliflower mosaic virus (CaMV) 35 S promoter, the plants display a reduction in shoot stature with rumpled or lobed leaves and (in some plants) a loss of apical dominance and severe dwarfism with meristematic tissue forming in inappropriate places [ $\left.8^{\circ}\right]$. These results indicate that the $K N 1$ product is associated with indeterminate growth and cell divisions, although the lack of recessive (loss-of-function) alleles of KN1 prevents a complete understanding of the role of this gene.

In addition to the $K n 1$ mutations, other dominant maize mutations affect leaf cell fate, including mutations of the Rough sheath1 (RS1) and Liguleless ( $L g 3$ and Lg4) genes [9]. A detailed examination of the Rs1-0 mutant has shown that it is similar to $K n 1$ mutants; each possesses dominant neomorphic mutations that act non cell autonomously to cause a transformation of blade tissue to sheath, although the Rs 1 mutant differs in that it affects the entire lateral dimension of the ligular region of the leaf, causes affected tissue to display attributes of both sheath and auricle, and does not show a dose response [10']. Although the normal role of $R S 1$ cannot be determined directly by analyzing the neomorphic mutant phenotype, the RS1 gene has recently been found to encode a KN1-like homeodomain protein (P Becraft, $\mathrm{M}$ Freeling, unpublished data cited in $\left.\left[9,10^{\circ}\right]\right)$. Coincidentally, the $R S 1$ gene was one of several maize homeobox genes cloned by members of the Hake laboratory

\footnotetext{
Abbreviations

CaMV-cauliflower mosaic virus; GL1-GLABRA1; KN1_KNOTTED1; RS1_Rough sheath1; TTG-TRANSPARENT TESTA-GLABRA.
} 
$\left[5,11^{\circ \bullet}\right]$ by virtue of their sequence similarity to $K N 1$. The expression of four of these maize hotneobox genes ( $K N 1, R S 1, K N O X 3$, and $K N O X 8$ ) has been examined in detail, and in wild-type plants, transcripts from each gene have been shown to accumulate in shoot meristems and the developing stem, but not in determinate lateral organs such as leaves or floral organs, nor in root meristems [11*]. Overall, the pattern of expression of $K N O X 8$ is similar to that of $K N 1$, whereas the RS1 and KNOX3 genes are expressed in only a subset of KN1-expressing cells. The expression of these four genes in the vegetative shoot apical meristem appears to predict the site of leaf initiation, as well as portions of the segmentation unit of the shoot ("phytomer') [11॰日]. The distinct regions of homeobox gene expression are suggestive of roles for the gene products in defining regional identities within the meristem which influence the fate of differentiating cells.

\section{Cloned homeobox genes associated with developmental abnormalities}

The role of plant homeobox genes in cell differentiation has also been studied in other plant species. A $K N 1$-like homeobox gene isolated from rice (OSH1) produces alterations in leaf morphology reminiscent of those in $K n 1$ mutants when introduced (in multiple copies) into rice [12*]. When the OSH1 cDNA is expressed in Arabidopsis (under CaMV35S control) or tobacco (under the control of various promoters), plant morphology is altered dramatically, with abnormalities in shoots, leaves, and flowers, and the formation of excess meristematic tissue $\left[12^{\bullet}, 13\right]$. The $O S H 1$ gene appears normally to be expressed in vegetative shoot apices [12•] which, when taken together with the cDNA data, implies that it like $K N 1$ ) may be a regulator of cell differentiation in/near the shoot meristem.

Using reduced-stringency DNA hybridization, a large number of homeobox genes have been identified from Arabidopsis, and one subfamily has been shown to be characterized by a leucine zipper motif adjacent to the homeodomain (denoted HD-Zip proteins) [14-16]. One HD-Zip gene, HAT4, may play a general role in plant development. Its transcripts accumulate in all tissues examined, with highest levels in stems and leaves [170]. Transgenic plants expressing an antisense CaMV35S-HAT4 gene construct display a general delay in development, whereas plants expressing a CaMV35S-HAT4 sense construct are tall and develop rapidly $\left[17^{\bullet}\right]$. It is not clear whether cell fates are altered in these plants or whether the only effect is on the rate of cell formation and differentiation. A member of another Arabidopsis homeobox gene subfamily has been identified because its product (HAT3.1) binds to a portion of the photoregulated cab-E promoter [18]. HAT3.1 lacks the leucine zipper motif found in the HD-Zip proteins and has an amino-terminal region similar to metal-binding domains (denoted the PHD-finger), but no direct evidence for a role in plant development has (yet) been obtained [18].

\section{Control of epidermal cell fate in Arabidopsis}

The formation of hair-bearing and hairless cells in the shoot and root epidermis of Arabidopsis provides a useful model for the study of cell fate specification. In the shoot epidermis, some of the cells differentiate into trichomes (leaf hairs), and genetic studies have shown that two loci, GLABRA1 (GL1) and TRANSPARENT TESTAGLABRA (TTG), are required for the specification of a trichome cell. The GL1 gene encodes a product with similarity to the DNA-binding domain of the $m y b$ family of transcriptional regulators [19], and it appears to act locally in trichome precursor cells, as evidenced by in situ RNA hybridization [20'] and genetic mosaic analyses [21॰]. Interestingly, two pieces of evidence indicate that $G L 1$ is not only required for specifying cell fate, but also to maintain trichome cell differentiation. First, a weak allele of the $g / 1$ gene $(g / 1-2)$ which is associated with the loss of 27 amino acids from the carboxyl terminus of the protein generates a small number of trichomes, with some aborted trichomes that cease expanding before reaching full size [22]. Second, GL1 transcripts persist in the differentiating trichome cells after expression in the surrounding leaf primordia has decreased [20']. These results imply that GL1 may be needed to maintain the expression of genes involved in cell morphogenesis.

The other gene required for trichome cell specification, TTG, may encode or activate a homolog of the maize $R$ gene product [23]. Trichome (and anthocyanin) production is restored to ttg mutant plants when a cDNA from the $L c$ gene of the maize $R$ family is introduced under the control of the CaMV35S promoter [23]. The $R$ gene family members encode proteins with a basic domain containing a helix-loop-helix (HLH) motif, similar to that found in the $m \gamma c$ class of DNA-binding proteins, and an acidic domain characteristic of transcriptional activators $[24,25]$. In maize, the $m \gamma c$-related $R$ gene product and the $m \gamma b$-related $C 1$ product are required to activate transcription of genes encoding flavonoid biosynthetic enzymes (reviewed in [26]). Thus, an attractive possibility is that the TTG gene may encode a $m \gamma c$-related product that interacts with the $m \gamma b$-related GL1 to activate trichome cell differentiation in the developing shoot epidermis. The TTG gene may also play a role in trichome spacing, as the $R$-expressing Arabidopsis plants produce excess trichomes over the leaf surface [23]. Trichome spacing is also affected in a newly isolated mutant, TRIPTYCHON (Tr $)$, which exhibits nests or clusters of trichomes on the leaf, implying that the affected gene may normally prevent cells adjacent to a trichome precursor from differentiating in the same manner $\left[21^{\circ}\right]$. 
In the root epidermis, cells differentiate to form either root hair cells or hairless cells. In Arabidopsis, the fate of immature epidermal cells is related to their position; cells located over an anticlinal wall separating underlying cortical cells differentiate into root hair bearing cells, and the other epidermal cells differentiate into mature hairless cells. Recently, the TTG gene has been found to participate in the specification of root epidermal cell fate, as $t t g$ mutants produce root-hair cells in all epidermal positions, and Arabidopsis expressing the maize $R$ gene generate hairless cells in all positions [27]. This indicates that TTG normally acts at an early stage in root epidermis differentiation to generate or respond to a position-dependent signal which influences cell fate. This also demonstrates overlap in the genetic control of cell differentiation in the shoot and root epidermis, although, interestingly, alterations in TTG action affect the root and shoot epidermis in opposite ways. Recessive ttg mutations cause excess root hair production and a lack of trichomes, whereas $R$ expression results in excess trichomes and a reduction in root hair formation $[23,27]$. It may be that the ground state is different in these two tissues, with a hairless cell the ground state for the shoot epidermis and a hair-bearing cell the ground state for the root epidermis.

\section{Genes controlling plant cell morphogenesis}

Once cell fate is specified, the differentiating plant cell initiates a program of cell morphogenesis. The complexity of this process is reflected by the finding of at least 18 genes that are required for the morphogenesis of a trichome cell in Arabidopsis $\left[21^{\bullet}, 28\right]$. The genetic analysis of trichome formation indicates that it is the result of many independent events, rather than a sequential stepwise process, with some of the events being dependent on the cell reaching a certain size [21 $\left.{ }^{\circ}\right]$. One of the trichome morphogenesis genes, GLABRA2 (GL2), has been cloned recently [2900]. Plants homozygous for a $g 12$ mutation produce trichomes with a laterally expanded shape, indicating a defect in trichome outgrowth $\left[21^{\circ}, 29^{\circ} \cdot\right]$. The product of the GL2 gene is a novel type of plant homeodomain protein which lacks the leucine zipper motif of the Arabidopsis HD-Zip proteins and the PHD-finger motif of the HAT3.1 protein [2900]. The GL2 transcripts are detected in individual developing trichome cells of the emerging leaf primordia $\left[29^{\circ} \cdot\right]$, consistent with the results of genetic mosaic analysis [ $\left.21^{\circ}\right]$, indicating that $G L 2$ may activate downstream genes associated with the expansion of trichome cells.

Many investigators interested in plant cell morphogenesis have been attracted recently to the study of the Arabidopsis root. Major reasons are its small size and remarkably simple structure $\left[30^{\bullet}, 31^{\bullet}\right]$. The Arabidopsis root apical meristem is composed of three tiers of putative initials that divide regularly to generate the longitudinal files of cells in the various tissues [31']. Cell morphogenesis can be analyzed along individual cell files, with 'younger' cells present near the root apex and 'older' (more differentiated) cells further from the apex. Several Arabidopsis root morphogenesis mutants have been isolated and characterized recently $\left[32,33^{\circ}\right]$. Three mutants display excessive cell expansion that is limited primarily to a single cell layer in each mutant (cobra mutant-expanded epidermis, sabre mutant-expanded cortex, and lion's tail mutant-expanded stele), indicating that the affected genes regulate cell expansion in a cell type specific manner [33०]. Mutants in which morphogenesis of Arabidopsis root hair cells is affected have also been identified and subdivided into those in which either root hair emergence or root hair tip growth is affected [34]. One of these mutants has been found to display abnormal pollen tube growth as well, which suggests that the affected gene (TIP1) is required for the morphogenesis of both of these tip-growing cell types [35]. Root hair morphogenesis mutants have also been identified recently in maize [36].

\section{Conclusions}

Molecular genetic approaches have led to new insights into the control of plant cell differentiation. One of the themes that is beginning to emerge from these studies is that plant cell differentiation appears to be governed, at least in part, by regulatory molecules with putative DNA-binding domains related to those present in some vertebrate and Drosophila proteins (e.g. homeodomains, Myb, and Myc domains). In these instances, it will be important to determine how the distribution of these regulatory molecules is controlled during plant development, and what the downstream targets of these regulatory molecules might be. There are many possible types of such downstream targets. Because cell position is known to be important in specifying fate, one class of targets may be genes encoding components of the cell wall (plant extracellular matrix) involved in cell-cell communication. In vertebrates and Drosophila, cell adhesion and substrate adhesion molecules have been implicated recently as targets of some of the homeodomain proteins [37], and the influence of the cell wall in algal cell fate has recently been documented during early development in Fucus [38॰]. It is also possible that a class of downstream target genes may tie into pathways of plant hormone action, as hormones can markedly affect plant cell morphogenesis. Finally, another class of targets may be genes encoding regulators of the plant cytoskeleton, as microtubule and microfilament systems reorganize during cell differentiation and influence the shape of plant cells. 


\section{Acknowledgement}

I thank members of the laboratory and colleagues in the field for helpful suggestions and for sharing unpublished data and manuscripts.

\section{References and recommended reading}

Papers of particular interest, published within the annual period of review, have been highlighted as:

- of special interest

-. of outstanding interest

1. Irish VF: Cell Lineage in Plant Development. Curr Opin Genet Dev 1991, 1:169-173.

2. Lord EM, Sanders LC: Roles for the Extracellular Matrix in Plant Development and Pollination: A Special Case of Cell Movement in Plants. Dev Biol 1992, 153:16-28.

3. Gehring WJ: Homeo Boxes in the Study of Development. Science 1987, 236:1245-1252.

4. Scott MP, Tamkun JW, Hartzell GW: The Structure and Function of the Homeodomain. Biochim Biophys Acta 1989, 989:25-48.

5. Vollbrecht E, Veit B, Sinha N, Hake S: The Developmental Gene Knotted-1 is a Member of a Maize Homeobox Gene Family. Nature 1991, 350:241-243.

6. Hake S: Unraveling the Knots in Plant Development. Trends Genet 1992, 8:109-114.

7. Smith LG, Greene B, Veit B, Hake S: A Dominant Mutation in the Maize Homeobox Gene, Knotted-1, Causes Its Ectopic Expression in Leaf Cells with Altered Fates. Development 1992, 116:21-30.

8. Sinha NR, Williams RE, Hake S: Overexpression of the Maize - Homeobox Gene, KNOTTED-1, Causes a Switch from Determinate to Indeterminate Cell Fates. Genes Dev 1993, 7:787-795.

The maize KNI CDNA was expressed in tobacco plants under the control of the CaMV35S promoter and caused alterations in cell fates in the shoot.

9. Freeling M: A Conceptual Framework for Maize Leaf Development. Dev Biol 1992, 153:44-58.

10. Becraft PW, Freeling M: Genetic analysis of Rough sheath 1 Developmental Mutants of Maize. Genetics 1994, 136:295-311. A detailed analysis of RsI mutants shows that in many ways they are phenotypically and genetically similar to the $K n 1$ mutants. Genetic mosaics containing sectors of wild-type Rs $1+$ tissue present in a mutant background exhibited a mutant phenotype, indicating that Rs $1-0$ acts in a non cell autonomous and non tissue specific fashion and may be involved in cell signaling.

11. Jackson D, Veit B, Hake S: Expression of Maize KNOTIEDI Re-. lated Homeobox Genes in the Shoot Apical Meristem Predicts Patterns of Morphogenesis in the Vegetative Shoot. Development 1994, 120:405-413.

An interesting paper documenting distinct expression patterns for four homeobox genes from maize (including $K N 1$ and $R S 1$ ) which implies roles in defining meristem boundaries. No evidence was obtained to support the possibility of direct interactions between the KN1 and the other three genes in controlling their expression. The $K N 1$ protein is suggested to act directly as an intercellular signal to explain differences between protein and RNA accumulation patterns.

12. Matsuoka $M$, Ichikawa $H$, Saito $A$, Tada $Y$, fujimura $T$, Kano- Murakami Y: Expression of a Rice Homeobox Gene Causes Altered Morphology of Transgenic Plants. Plant Cell 1993, 5:1039-1048.

The isolation and characterization of a rice homeobox gene (OSH1) very similar to the maize KNI gene is described. Expression of this gene in Arabidopsis was shown to alter vegetative and reproductive development.
13. Kano-Murakami Y, Yanai T, Tagiri A, Matsuoka M: A Rice Homeotic Gene, OSH1, Causes Unusual Phenotypes in Transgenic Tobacco. FEBS Lett 1993, 334:365-368.

14. Ruberti I, Sessa G, Lucchetti S, Morelli G: A Novel Class of Plant Proteins Containing a Homeodomain with a Closely Linked Leucine Zipper Motif. EMBO / 1991, 10:1787-1791.

15. Schena M, Davis RW: HD-Zip Proteins: Members of an Arabidopsis Homeodomain Protein Superfamily. Proc Natl Acad Sci USA 1992, 89:3894-3898.

16. Mattsson J, Soderman E, Svenson $M$, Borkird C, Engstrom P: A New Homeobox-Leucine Zipper Gene from Arabidopsis thaliana. Plant Mol Biol 1992, 18:1019-1022.

17. Schena M, Lloyd AM, Davis RW: The HAT4 Gene of Ara- bidopsis Encodes a Developmental Regulator. Genes Dev 1993, 7:367-379.

This papers describes a functional analysis of one of the members of the Arabidopsis HD-Zip homeobox gene family and suggests a role for the product in a general plant developmental process.

18. Schindler U, Beckmann H, Cashmore AR: HAT3.1, a Novel Arabidopsis Homeodomain Protein Containing a Conserved Cysteine-Rich Region. Plant / 1993, 4:137-150.

19. Oppenheimer DG, Herman PL, Sivakumaran S, Esch J, Marks MD: A myb Gene Required for Leaf Trichome Differentiation in Arabidopsis is Expressed in Stipules. Cell 1991, 67:483-493.

20. Larkin IC, Oppenheimer DG, Pollock SM, Marks MD: The - Arabidopsis GL1 Gene Requires Downstream Sequences for Function. Plant Cell 1993, 5:1739-1748.

This report describes the in situ localization of the $G L 1$ transcript in developing trichome cells and shows that an enhancer-like element responsible for this expression pattern is located in a $3^{\prime}$ region.

21. Mulskamp $M$, Misera $S$, Jurgens $G$ : Genetic Dissection - of Trichome Cell Development in Arabidopsis. Cell 1994, 76:555-566.

A large-scale genetic screen led to the identification of more than 70 trichome mutants which represent 21 different genes affecting Arabidopsis trichome formation. Morphological characterization, the construction of genetic mosaics, and endoreplication analysis were used to define a genetic pathway for trichome development.

22. Esch J), Oppenheimer DG, Marks MD: Characterization of a Weak Allele of the GL1 Gene of Arabidopsis thaliana. Plant Mol Biol 1994, 24:203-207.

23. Lloyd AM, Walbot V, Davis RW: Arabidopsis and Nicotiana Anthocyanin Production Activated by Maize Regulators $R$ and C1. Science 1992, 258:1773-1775.

24. Ludwig SR, Habera LF, Dellaporta SL, Wessler SR: LC, a Member of the Maize $R$ Gene Family Responsible for Tissue-Specific Anthocyanin Production, Encodes a Protein Similar to Iranscriptional Activators and Contains the myc-Homology Region. Proc Natl Acad Sci USA 1989, 86:7092-7096.

25. Consonni G, Geuna F, Gavazzi G, Tonelli C: Molecular Homology Among Members of the $R$ Gene Family of Maize. Plant J 1993, 3:335-346.

26. Van der Meer IM, Stuitje AR, Mol JNM: Regulation of General Phenylpropanoid and Flavonoid Gene Expression. In Control of Plant Gene Expression. Edited by Verma DPS. Boca Raton, Florida: CRC Press, Inc; 1992:125-155.

27. Galway ME, Masucci JD, Lloyd AM, Walbot V, Davis RW, Schiefelbein JW: The TIC Gene is Required to Specify Epidermal Cell fate and Cell Patterning in the Arabidopsis Root. Dev Biol 1994, in press.

28. Marks MD, Esch Jj: Trichome Formation in Arabidopsis as a Genetic Model for Studying Cell Expansion. Curr Top Plant Biochem Physiol 1992, 11:131-142.

29. Rerie WG, Feldmann KA, Marks MD: The CLABRA2 Gene En-. codes a Homeodomain Protein Required for Normal Trichome Development in Arabidopsis. Genes Dev 1994, 8:1388-1399. This reports the exciting finding of a new type of plant homeobox gene and shows that it is expressed in developing trichomes. The GL2 product is likely to regulate cell expansion during trichome development. 
30. Aeschbacher RA, Schiefelbein JW, Benfey PN: The Genetic and - Molecular Basis of Root Development. Annu Rev Plant Physiol Mol Biol 1994, 45:25-45.

A comprehensive review of recent studies of root development with particular emphasis on genetic approaches with Arabidopsis.

31. Dolan L, Janmaat K, Willemsen V, Linstead P, Poethig S, Roberts - K, Scheres B: Cellular Organization of the Arabidopsis thaliana Root. Development 1993, 119:71-84.

This study characterizes the organization of the developing Arabidopsis root and describes its strikingly simple structure. A model is proposed for the organization of the root apical meristem, including the putative initials for each tissue.

32. Baskin TI, Betzner AS, Hoggart R, Cork A, Williamson RE: Root Morphology Mutants in Arabidopsis thaliana. Aust / Plant Physiol 1992, 19:427-438.

33. Benfey PN, Linstead PJ, Roberts K, Schiefelbein JW, Hauser $M$, Aeschbacher RA: Root Development in Arabidopsis Four Mutants with Dramatically Altered Root Morphogenesis. Development 1993, 119:57-70.

This report outlines the isolation of root morphogenesis mutants of Arabidopsis. The characterization of four of these mutants shows that each of the affected genes largely controls the morphogenesis of a single cell layer.

34. Schiefelbein JW, Somerville C: Genetic Control of Root Hair Development in Arabidopsis thaliana. Plant Cell 1990, 2:235-243.
35. Schiefelbein J, Galway $M$, Masucci J, Ford S: Pollen Tube and Root-Hair Tip Growth is Disrupted in a Mutant of Arabidopsis thaliana. Plant Physiol 1993, 103:979-985.

36. Wen T-J, Schnable PS: Analyses of Mutants of Three Genes that Influence Root Hair Development in Zea mays (Graminese) Suggest that Root Hairs are Dispensable. Am J Bot 1994, 81:833-842.

37. Edelman GM, Jones FS: Outside and Downstream of the Homeobox. I Biol Chem 1993, 268:20683-20686.

38. Berger F, Taylor A, Brownlee C: Cell Fate Determination by - the Cell Wall in Early fucus Development. Science 1994, 263:1421-1423.

The cell wall is implicated in the control of cell fate in the two-celled embryo of Fucus spiralis. The contact of one of the two cells of the early embryo with the isolated cell wall of the other caused a switch in cell fate.

JW Schiefelbein, Department of Biology, 830 North University Avenue, University of Michigan, Ann Arbor, Michigan 481091048, USA. 